\title{
Significant events during a psychodrama and action methods based experiential group training for psychology students
}

\author{
Krzysztof Mariusz Ciepliński • Joanna Karkut-Rzondtkowska
}

Published online: 19 March 2019

(C) The Author(s) 2019

\begin{abstract}
This article of the Zeitschrift für Psychodrama und Soziometrie (ZPS) presents some results of empirical research on the change process during the psychological training based on Psychodrama and Action Methods. The participants were a group of 28 female, aged 22, fourth year Psychology students at the John Paul II Catholic University of Lublin, Poland. They are randomly chosen from a group of 61 voluntaries and divided into two equal groups. 24-hour three-day training were prepared and conducted by a certified psychotherapist and PD trainer. Participants were anonymously asked by using the Polish version of the Helpful Aspects of Therapy Form (HAT) adapted to the training context for their feedback at the end of each eighth-hour day of training as well as three months after. The students reported many significant events both helpful and hindering. Helpful events were more numerous in number. Some of these were still remembered after three months. The trainees' perception of the application of a set of PD and AM techniques in their academic professional education, as well as the use of HAT as feedback methods in group training were discussed.
\end{abstract}

Keywords Change Process · Helpful Aspects of Training - Experiential Learning · Empirical Research · Psychodrama - Significant Events $\cdot$ Students Training Groups · Action Methods

K. M. Ciepliński, PhD (₫)

Department of Psychotherapy and Health Psychology, The John Paul II Catholic University of Lublin, Lublin, Poland

E-Mail: k.cieplin@gmail.com

J. Karkut-Rzondtkowska, M.A.

Warsaw, Poland

E-Mail: karkut.joanna@gmail.com 


\section{Bedeutsame Ereignisse während eines selbsterfahrungsorientierten Gruppentrainings für Psychologiestudenten - auf der Basis von Psychodrama und Aktionsmethoden}

Zusammenfassung Dieser Beitrag der Zeitschrift für Psychodrama und Soziometrie (ZPS) stellt die Resultate einer empirischen Studie über Veränderungen während eines psychologischen Trainings auf der Grundlage von Psychodrama und Aktionsmethoden vor. Die Teilnehmerinnen waren eine Gruppe von 28 Psychologiestudentinnen im Alter von 22 Jahren an der Katholischen Universität Johannes Paul II. in Lublin, Polen. Sie waren zufällig aus einer Gruppe von 61 Freiwilligen ausgewählt und in zwei gleiche Gruppen aufgeteilt worden. Das dreitägige, insgesamt 24-stündige Training wurde von einem zertifizierten Psychotherapeuten und PsychodramaTrainer vorbereitet und durchgeführt. Die Teilnehmerinnen wurden anonym befragt, indem sie die polnische Version des an den Trainingskontext angepassten Formats des Fragebogens „Hilfreiche Aspekte der Therapie“ (HAT) erhielten. Sie wurden an jedem Tag des Trainings sowie drei Monate danach zu ihrem Feedback befragt. Die Studentinnen berichteten von vielen bedeutenden Ereignissen, die sowohl als hilfreich als auch als hinderlich eingeschätzt wurden. Die hilfreichen Veranstaltungen überwogen. Einige davon waren drei Monate später noch in der Erinnerung. Die Wahrnehmung und Beurteilung der Auszubildenden bezüglich der Anwendung einiger Psychodrama- und Aktionsmethoden in ihrer akademischen Berufsausbildung sowie bezüglich des Einsatzes des HAT als Feedback-Methode im Gruppentraining werden diskutiert.

Schlüsselwörter Hilfreiche Aspekte des Trainings · Handlungsorientiertes Lernen · Empirische Forschung · Psychodrama · Bedeutsame Ereignisse · Studenten-Trainingsgruppen $\cdot$ Aktionsmethoden

\section{Introduction}

Psychodrama and related action methods are used in many different contexts and fields of application, e.g.: clinical, as a psychotherapy method, educational, social and organizational work (Kellerman 1992; Stadler 2014; Schaller 2016; Kunz Mehlstaub and Stadler 2018). One of the forms of its application is adult education and training conducted within the frame of academic institutions (Ciepliński 2014). Ciepliński formulated three general assumptions of the use of psychodrama elements in the process of psychology students' education:

- Psychodrama is a method of treatment and training based on human potential for role playing and experiential learning;

- Students should develop their theoretical knowledge as well as practical competencies;

- Some PD techniques can be helpful for the professional and personal development of psychology students. 
In the current program of the Psychology Institute at the John Paul II Catholic University of Lublin (KUL), Poland, psychodrama elements are applied among others in the following areas:

- psychotherapy lectures, where some PD techniques like role playing and doubling are used as an educational dramatic illustration of the theoretical concepts and ideas relating to the situation of psychological treatment;

- classes on educational projects preparation conducted for Business and Entrepreneurship Psychology students including the basic knowledge about the main concepts and terms of J.L. Moreno theory, as well as the most important psychodrama methods and tools; psychodrama is used to develop students' core trainer competencies;

- interpersonal training, based on the here-and-now spontaneous communication in the group; some psychodrama techniques (like doubling, two chairs technique, sociometry) are used as supplementary methods of group process stimulation;

- PD-based experiential group training focused on group process and core psychological competence learning. The educational goals of the training are the following:

- providing students with personal experiences and knowledge on typical shortterm small group processes (learning through self-experience);

- familiarizing them with selected psychodrama and action methods techniques used in group counselling and psychotherapy

- enhancing their core professional psychological competencies, e.g.: selfawareness, interpersonal communication skills and co-operation in the group (Ciepliński 2014, 2018).

Planning a self-experience training for university students conducted as obligatory classes a trainer should reflect not only on the educational but also the ethical aspects of applied interventions. Students are not required to participate in the process of psychiatric diagnosis or psychotherapy. Before as well as after the training they can meet each other in every day educational and informal contexts. The use of full repertoire of PD techniques would be conducive to exploitation of the therapeutic potential of psychodrama (Kellerman 1992), but at the same time, could facilitate an externalisation of deep personal distress experiences and traumatic personal life events. These should not be treated in the educational group. According to Ciepliński $(2014,2018)$ psychodrama in its classic form does not entirely fit to the university education context. It is worth mentioning that the discussion on the limitations of traditional PD approach in group work and group research is nothing new in the psychodrama literature. It was expressed and discussed already twenty years ago by David Kipper (1997), who identified and postulated to develop a new, more capacious, eclectic and flexible models of psychodrama group work. In connection with this way of thinking, Ciepliński proposed to use the fixed elements of psychodrama and action methods in the university education (in particular connected with role taking and playing, "here-and-now" interpersonal contact through the roles, as well as vignettes, group games and sociometries matched to a phase of the group development), rather than a classical psychodramatic treatment concept (first of all 
connected with the sequential protagonist work) focused on working with the participants' significant personal experiences. The group conducted according this model is called "Psychodrama-based" (process-focused experiential training groups) rather than "simply" "psychodramatic" group (especially in the classical meaning of this term). Ciepliński allows for the implementation of other action methods techniques in the group too. As a consequence, from the formal point of view this kind of group could be also recognised as mixed method based group.

\section{Method}

The research presented in this study was conducted between November 2016 and March 2017 as part of a wider scientific project entitled: Effectiveness and personal change processes in the PD-based group training for psychology students (EPCPProject) carried out at the KUL Psychotherapy and Health Psychology Department which was elaborated and directed by Krzysztof Ciepliński, PhD. The project was assessed and approved by the Ethical Committee of the KUL Psychology Institute.

Participants were female fourth year KUL Psychology of Promoting the Quality of Life students $(N=28$, average age 22) randomly selected from among 61 students who volunteered to participate in the EPCP-Project. During the process of application they were informed about the goals, structure and non-therapeutic character of the training. In addition, a general description of the training was published on the KUL Institute of Psychology Website. Students were randomly divided into two 24-hour three-day PD-based self experience-group training with 14 participants conducted by a certified psychotherapist and psychodrama trainer.

Both groups worked according to a very similar content and structure elaborated by K. Ciepliński (2014) with supervision from Hilde Gött. The team of KUL Business and Entrepreneurship Psychology students additionally participated in the project as observers and co-researchers. Their task was to observe and record the course of the training, including a description of its structure, trainers' interventions and participants' reactions as well as handing out and returning envelopes with the research questionnaires. Some research results of the EPCP-Project were used in the preparation of their master's degree thesis, promoted by Dr. hab. Agnieszka Kulik and Dr. Krzysztof Ciepliński. The research outcomes presented in this article were utilized in the master paper of Joanna Karkut-Rzondtkowska (2017).

The following psychodrama and action methods techniques were used during the training:

- warm-up exercises (walking around the room, non-verbal greetings, pantomime and psychological gymnastics)

- psychodrama rituals based on non-verbal activities (e.g. contract ritual)

- spontaneity and creativity training (e.g.: role taking and playing, communication using self-made musical instruments, pantomime communication)

- techniques which supported group contact and cohesion (e.g. back massage in a circle)

- vignettes (individual "way" to the training group, group vignettes) 
- group games ("two kingdoms")

- exercises clarifying the group process (e.g. group sharing, empty chair technique, maps of emotions and group motives)

- sociometric techniques-exemplary criteria: the most well-known/least-known participants at the beginning of the group process, "place of living", "plans for the future", the participants' position among siblings in their family, personal preferences, participants' perceived position in the group

- verbal and non-verbal communication and sharing techniques (arranging dialogues in pairs, sharing personal experiences within the group, playing-by expressing emotions)

- exercises designed to build self-awareness and self-distancing (visualization and role-playing, self-introduction taking the role of an object)

- emotional catharsis and closure exercises ("crowded tram", "car wash", "the entrance to the circle", directed and free vocalization, standing or lying on the floor in a circle)

- psychodramatic conflict management and feedback techniques (e.g.: "chairs technique")

Due to ethical objections explained above, psychodrama with a protagonist was not used.

The training started with a discussion on confidentiality and other important rules supporting secure and effective group work accepted by all participants. Six-hour group content and process analysis based on the participants' teams' written elab-

Table 1 Helpful events in the Training Group 1

\begin{tabular}{llll}
\hline Helpful events & $N$ & M & Training phase \\
\hline Sociometry/Sociodrama exercises & 5 & 7.01 & TD1 \\
Vignette "My way to this group" & 5 & 7.10 & TD1 \\
Group sharing & 4 & 8 & TD1 \\
Group contract ritual & 2 & 8.5 & TD1 \\
Getting to know each other & 1 & 8 & TD1 \\
Group play "Two kingdoms" & 11 & 8 & TD2 \\
Role playing in pairs & 3 & 6.83 & TD2 \\
Verbal communication in pairs & 2 & 8.5 & TD2 \\
"Two kingdoms"-feedback from the roles & 2 & 7.5 & TD2 \\
Empathic look at other people & 1 & 8 & TD2 \\
De-rolling ritual & 1 & 5 & TD2 \\
Sociometric feedback & 9 & 8.2 & TD3 \\
Final feedback in the group & 5 & 8.4 & TD3 \\
Non-verbal contact in pairs & 4 & 7.25 & TD3 \\
Group vocalization lying on the floor in the dark- & 3 & 8.66 & TD3 \\
ness & & & TD3 \\
Positive psychological climate in the group & 1 & 8 & TD3 \\
Relaxation and integration of the group & 1 & 9 & TD1-3 \\
In Total & $\mathbf{6 0}$ & $\mathbf{7 2}$ & \\
\hline
\end{tabular}

$M$ means of event rating 
Table 2 Hindering events in the Training Group 1

\begin{tabular}{llll}
\hline Helpful events & $N$ & M & Training phase \\
\hline Vignette "My way to this group" & 2 & 3 & TD1 \\
Sociometry exercises & 1 & 3 & TD1 \\
Warm-up exercises & 1 & 3.5 & TD1 \\
"Two kingdoms"-feedback from the role & 2 & 3.5 & TD2 \\
Verbal communication in pairs & 2 & 3 & TD2 \\
Role playing in pairs & 1 & 3 & TD2 \\
Sociometric feedback & 3 & 1.33 & TD3 \\
Role playing in the group & 2 & 3.5 & TD3 \\
Non-verbal contact in pairs & 1 & 4 & TD3 \\
Tension and tiredness at the beginning of the & 1 & 2 & TD3 \\
group session & & & \\
In Total & $\mathbf{1 6}$ & $\mathbf{2 . 8 4}$ & TD1-3 \\
\hline
\end{tabular}

orations supplemented by the trainer's comments and explanations was conducted 1-2 weeks after completing the training. Additionally, students were familiarised with the psychodrama theory during the course of the psychotherapy lecture as well as individual readings of suggested psychodrama literature.

The aim of the present research was to explore the participants' perception of their individual changes during the training. The Helpful Aspects of Therapy Form (HAT) (Elliott 1993; Llewelyn 1988) translated into Polish and adapted to the training context by K. Ciepliński was used. HAT is a self-reporting questionnaire based on the assumption of the importance of the client's own perception of the helpful and hindering factors in their process of change (Elliott and Shapiro 1988). In particular using the original version of HAT, clients are asked to identify and to rate the significant (both helpful and hindering) events during their treatment session on the 9-point Likert-type scale. HAT is accounted to Patient Generated Measures (PGM) (Sales and Alves 2016). The Polish version used in this study (PAT) included original authors' questions addressed to the training experiences of the participants. The trainees were asked to fill the paper version of PAT after each day of training (TD1, TD2, TD3) as well as three months after completing it. The research data was anonymized by using a randomly chosen unique identifier for each respondent.

\section{Results}

\subsection{Significant events in the training group 1}

Students from the first group identified a total of 60 helpful events during all phases of training. Some identified more than one event on each training day. The events were rated mostly as moderately and greatly helpful (rating 7 and 8). Some were rated as extremely helpful (9). The particular information about students' choices and ratings is presented in Table 1. 
Table 3 Helpful events in the Training Group 2

\begin{tabular}{llll}
\hline Helpful events & $N$ & M & Training phase \\
\hline Vignette "My way to this group" & 12 & 7 & TD1 \\
Introduction to role reversal & 3 & 7.67 & TD1 \\
Sociometry/Sociodrama exercises & 2 & 7 & TD1 \\
Integration in the group & 2 & 7 & TD1 \\
Atmosphere of trust in the group & 1 & 9 & TD1 \\
Vignette "Map of emotions" & 1 & 8 & TD1 \\
Verbal communication in pairs & 7 & 7.4 & TD2 \\
Non-verbal contact/role playing in pairs & 3 & 7.33 & TD2 \\
Group sharing and fedback & 2 & 8 & TD2 \\
Group play "Two kingdoms" & 2 & 7 & TD2 \\
Non-verbal contact/role playing in pairs & 11 & 7.91 & TD3 \\
Sociometric feedback & 6 & 8.2 & TD3 \\
Sharing and feedback in the group & 3 & 7.33 & TD3 \\
Group vocalization in the darkness & 1 & 8 & TD3 \\
In Total & $\mathbf{5 6}$ & $\mathbf{7 . 2}$ & TD1-3 \\
\hline
\end{tabular}

The trainees from the first group reported many psychological benefits associated with the helpful group events. On the first training day they pointed to the following: the experience of self-reflection and self-understanding; a new, inspiring view on the past personal and family experiences; deeper understanding of the sibling's role in the family; activating positive personal memories; feelings of inclusion and belonging to the group; sense of similarity to others; the self- and other participants' "openness"; atmosphere of acceptance and freedom in the group; experience of individual decision-making and responsibility. During the second day of training students pointed to the value of taking on new roles; playing; training and reflecting; deeper self-understanding; de-rolling and awareness of their own identity; affirmation from the group' involvement and cooperation in the group', self-distance and being open to new experiences. On the third training day the most important helpful experiences were connected first of all with the new knowledge about the personal and other participants' perception of the social position in the group; selftranscendence (breaking down) of personal fears and overcoming internal resistance in communication with others; atmosphere of acceptance and freedom; free expression in the group; as well as the experience of being close to others and unity in the group.

16 group events were perceived by the participants as hindering. Most of them were assessed as moderately (3) or slightly hindering (4). Single events were rated as extremely (1) or greatly hindering (2). Th particular information is compiled in Table 2.

The hindering experiences of participants of the TG1 were referring to disclosure in the group; time pressure; non-verbal contact; psychological distress connected to speaking in the group; not being able to understand the aim of an exercise; tension during role playing; awareness of their own personal tension and tiredness. During the procedure of sociometric feedback in the group two participants felt very anxious 
Table 4 Hindering events in the Training Group 2

\begin{tabular}{llll}
\hline Helpful events & $N$ & M & Training phase \\
\hline Vignette "My way to this group" & 3 & 2.42 & TD1 \\
Closeness of others in the group & 1 & 4 & TD1 \\
Life events preceding the training & 1 & 4 & TD1 \\
"Two kingdoms" group play & 7 & 2.34 & TD2 \\
Non-verbal contact/role playing in pairs & 2 & 3.5 & TD3 \\
Sociometric feedback & 2 & 2.75 & TD3 \\
In Total & $\mathbf{1 6}$ & $\mathbf{2 . 7 6}$ & TD1-3 \\
\hline
\end{tabular}

or tense; one participant felt pressed by the group trainer to disclose her sociometric choice.

\subsection{Significant events in the training group 2}

Participants of the second group identified a total of 56 helpful events at the time of their training. Some persons pointed to more than one event on each training day. Only one trainee did not find any helpful events on the second day of training. The events were rated mostly as slightly, moderately and greatly helpful (rating 6, 7, 8), and sometimes as extremely helpful (9). The particular information about participants' choices and ratings is presented in Table 3.

The participants of the second group perceived many helpful moments and experiences during the training. On the first training day the most important included acquiring new knowledge about their own values, choices and preferences in joining peer groups in life so far; the atmosphere of honesty, openness and trust; having an opportunity to break down own personal barriers in contact with others; an awareness of experienced feelings; liberation from blocked emotions; as well as a sense of similarity to others; deeper understanding of the sibling's role in their own life; and being able to reflect on the way others perceive them. On the second day students reported the importance of the sense of closeness to others; acquiring new knowledge about colleagues from the group; free emotional expression; and also the atmosphere of freedom and acceptance in the group. The additional components perceived as helpful included: positive feedback from the group; sense of freedom of verbal and non-verbal expression; obtaining a new perspective on their own experience; feelings of energy, joy, being active and cooperative; as well as the experience of close non-verbal contact. On the third training day participants experienced a trust and responsibility for others; they gained new knowledge about the personal and other participants' perception and attitudes to each other; felt the courage to express their own perception of others; felt a bond with others, as well as security and freedom in the group. They also experienced warmth and kindness from others.

16 group events were perceived as hindering by the participants. Most of them were assessed as greatly, moderately or slightly hindering (rating 2, 3, 4). Single events were rated as extremely hindering (1). This particular information is compiled in Table 4. 
For a few participants the same event (e.g. vignette "My way to this group") was simultaneously helpful and hindering. On the first day of training the hindering events were connected with the difficulties in disclosure and social exposition; perceived close attitudes of other participants and stressful pre-training life events. On the second day of the training, difficult experiences and feelings appeared during the group game "Two kingdoms". What many participants found hindering at that moment were difficulties with communication in the group as well as the process of the role taking and improvisation. On the last training day hindering experiences noted by participants included: tension during the close non-verbal contact in pairs and social anxiety connected with the sociometric feedback process.

\subsection{Perception of the significant events three months after the training}

Students were asked to fill PAT form three months after completing the training. Almost all participants gave their reports $(N=26), 24$ of them (more than 90\%) identified helpful events. About one third of trainees pointed also on hindering events ( $n=10$, two responders indicated only these). The perception of the significance of the group experiences three months after completing the training were relatively coherent to their opinions directly after the training. The most often indicated as helpful were: vignette "My way to this group"; group game "Two kingdoms"; participants similarities exploration by sociometry; sociometric feedback as well as role playing; and non-verbal communication with other participants. A few students expressed their general feelings of beneficial participation in psychodrama training, especially connected with getting new reflections about yourself; own family and social functioning and perception by the group. The experiences connected to the positive feedback from the group and moments of freedom in communication and emotional expression were also reported.

Hindering moments in the group were connected with the uncomfortable disclosure, embarrassment at playing and social exposition, tiredness and activating memories about difficult past experiences.

\section{Conclusions and discussion}

During process-focused psychodrama-based self-experience training group for psychology students' participants had many chances for interpersonal contact, social exposition, communication with others, and emotional exchange. They also had many occasions to reflect on their experiences. The research result shows that participation in the training relates to many significant events for the trainees (both helpful and hindering). In both groups, helpful events were much larger in numbers. Nobody reported lack of helpful events during the training. Many participants indicated more than one helpful event on the same training day. The coherence of perception of the particular elements of group training was specific for each group and was also dependent on the phase of the group process. Same group events were perceived by different participants both as helpful and hindering. The question regarding the factors affecting such personal assessment is very interesting. The results of the 
qualitative analysis of the trainees' reports suggest that the personal perception and rating of the group experiences is very individual and depends on many personal and group factors. Probably, the important components are: personal attitude and expectations towards the training; initial level of interpersonal competencies; life events preceding participation in the training; phase of the group process; perception of the emotional climate in the group and the leader's activity; other participants' social behaviors as well as the appearance of other significant group events. Research on this topic should be continued.

For some trainees the same group situation/event was perceived both as helpful and hindering. It proves that participation in this kind of intensive psychodramarelated training group can be simultaneously beneficial and challenging for trainees. The use of PD techniques facilitates spontaneity and provokes the process of externalization among participants. Some of them pointed directly to the significance of their personal decision to take an emotional risk of social exposure and disclosure in the group.

Rating of the significance of the group events three months after completing the training shows its relatively persistent, positive meaning for students. Most of them perceived beneficial effects related to the use of some psychodrama, sociodrama and sociometric techniques. Some students still remembered difficult moments in their training.

The research design of this study enabled only the recognition of the participants' personal perceptions and their attributions of the group events as helpful and hindering. Responders were asked to locate their significant experiences in concrete moments during the training. The precision of their feedback was varied. Most of the reports included indications on the particular PD techniques (or coherent groups of techniques), but some (especially received at the follow-up measurement) were more general, regarding the training as a whole. It is one of the limitations of this research. Another is related to the fact that the criteria of the assessment of group events as helpful or hindering were subjective (and probably non-coherent). What is more, the personal goals of the trainees connected with the participation in the training were not considered.

It could be interesting to replicate the study with the use of a more extended research scheme like a three-group design (with control group, psychodramatic and non-psychodramatic - e.g. psychodynamic - group training). It could provide important information about the specificity and usefulness of psychodrama-based interventions. It should be noted, that although this idea is valued from the scientific point of view, it is not easy to realize in the frame of semi-naturalistic studies ${ }^{1}$.

Previous research on the use of psychodrama for university and college students' was conducted mainly in the counseling and psychotherapy context (Çam 2016; Chae and Kim 2017; Dogan 2010; Ge et al. 2011). This study shows that also psychodrama-based group training conducted as a part of obligatory university classes strongly affects its participants. The results of the present study are promising, but

\footnotetext{
1 The complete research protocol applied in the EPCP-Project included also the use of other quantitative measurement methods as well as control groups of students not participating in the PD-based training groups. The final results of these will be published in a separate elaboration.
} 
due to its exploratory status one should be very cautious about the generalization of the findings. The research should be also continued in different groups, with different age and gender, conducted by other trainers, with different content and settings.

HAT is used in research on psychodrama psychotherapy (Gonzales and Lucas 2015; Cruz 2017; Sağin and Altan Egean 2017) as well as in psychodrama psychotherapy training (Fürst and Krall 2016). The outcomes of this study provide an argument for the successful adaptation of this tool to a basic training of psychological competencies. It can be useful for the exploration and understanding of the "cosmos" of group participants' experiences. Using it, a trainer can clarify and understand personal and group processes. The idea of ongoing monitoring of the process and of the clients' perception of the psychological treatment situation postulated in the discussion about the effectiveness of psychotherapy (Lambert 2010, 2017; Shimokawa et al. 2010; Burlingame et al. 2013; Thayer and Burlingame 2014) should be also taken into consideration in the context of psychological psychodramabased training. This study can be located among practice-oriented forms of research in psychodrama (Krall 2015; Sales 2015) and psychodrama group process research, which were strongly postulated by Indagator and Fung Chung (2013). It can be also categorized as a baby step towards the recognition of psychodrama as a researchinformed practice.

The outcomes show that a psychodramatist as a trainer must be aware of the "psychological power" of the methods applied in the group. Even if a trainer is not focused on a "deep" exploration of the participants' experiences (as in the training model presented in this study), the group situation as well as psychodrama specifics can provide not only helpful but also stressful and potentially harmful experiences for the participants. Responsibility and ethical sensibility during the use of psychodrama techniques have to be treated as a core competence of any psychodrama group leader.

Conflict of interest K.M. Ciepliński and J. Karkut-Rzondtkowska declare that the research was conducted in the absence of any commercial or financial relationships that could be construed as a potential conflict of interest.

Open Access This article is distributed under the terms of the Creative Commons Attribution 4.0 International License (http://creativecommons.org/licenses/by/4.0/), which permits unrestricted use, distribution, and reproduction in any medium, provided you give appropriate credit to the original author(s) and the source, provide a link to the Creative Commons license, and indicate if changes were made.

\section{References}

Burlingame, G., Strauss, B., \& Joyce, A. (2013). Change mechanisms and effectiveness of small group treatments. In M.J. Lambert (Ed.), Bergin \& Garfield's handbook of psychotherapy and behavior change (6th edn., pp. 640-689). New York: Wiley.

Chae, S.E., \& Kim, S.J. (2017). Group psychodrama for Korean college students. Journal of College Student Psychotherapy, 31, 59-70. https://doi.org/10.1080/87568225.2016.1239512.

Çam, O. (2016). The influence of psychodrama on promoting self-disclosure in groups of university students. In C. Stadler, M. Wieser \& K. Kirk (Eds.), Psychodrama. Empirical Research and Science 2 (pp. 255-274). Wiesbaden: Springer. https://doi.org/10.1007/978-3-658-13015-2_18.

Ciepliński, K. M. (2014). To understand yourself and others through the scene being portrayed. Elements of psychodrama in academic education of psychology students. Upper level Moreno's psychodrama training graduation paper. Unpublished manuscript 
Ciepliński, K. M. (2018). The use of psychodrama in psychology students education. FEPTO Research Committee Meeting, Leipzig, Germany. http://www.fepto.com/wp-content/uploads/FEPTO_RC_ Leipzig_report.pdf

Cruz, A.S. (2017). Practice based research in psychodrama: Making decisions about procedures and assessment protocols. http://www.fepto.com/wp-content/uploads/Skopje-FEPTO-RCM-2017-finalreport.pdf. Accessed 20 June 2018.

Dogan, T. (2010). The effects of psychodrama on young adults' attachment styles. The Arts in Psychotherapy, 37(2), 112-119. https://doi.org/10.1016/j.aip.2010.02.001.

Elliott, R. (1993). Helpful aspects of therapy form. http://www.experientialresearchers.org/instruments/ elliott/hat.html. Accessed 15 Apr 2015. Unpublished manuscript.

Elliott, R., \& Shapiro, D. A. (1988). Brief structured recall: A more efficient method for studying significant therapy events. British Journal of Medical Psychology, 61, 141-153. https://doi.org/10.1111/j.20448341.1988.tb02773.x.

Fürst, J., \& Krall, J. (2016). Integration von Forschung in der Psychotherapieausbildung - Erfahrungen von Studieren mit forschungsorientierten Inhalten und Tätigkeiten im Projekt TRAIN. In C. Stadler, M. Wieser \& K. Kirk (Eds.), Psychodrama. Empirical Research and Science 2 (pp. 255-268). Wiesbaden: Springer. https://doi.org/10.1007/s11620-015-0298-5.

Ge, Y., He, H., \& Dai, L. (2011). Study on group intervention regarding interpersonal trust among college students with campus psychodrama. Health, 3(7), 462-466. https://doi.org/10.4236/health.2011. 3707.

Gonzales, A., \& Lucas, P. (2015). Efficacy and change process in psychodrama. http://www.fepto.com/ wp-content/uploads/RC-Lisbon-report.pdf. Accessed 19 Sept 2018.

Indagator, Y., \& Fung Chung, S. (2013). A review of psychodrama and group process. International Journal of Social Work and Human Services Practice, 1(2), 105-114. https://doi.org/10.13189/ijrh.2013. 010204.

Karkut-Rzondtkowska, J. (2017). Psychological analysis of the process in the students' training group conducted with a psychodrama approach. Lublin: KUL. Unpublished master degree thesis

Kellerman, P. F. (1992). Focus on psychodrama. The therapeutic aspects of psychodrama. London: Jessica Kingsley Publishers.

Kipper, D. (1997). Classical and contemporary psychodrama: A multifaceted, action-oriented psychotherapy. The international Journal of Action Methods, 50(3), 99-107.

Krall, J. (Ed.). (2015). Report from the FEPTO research committee meeting. Action methods and experiential learning. Practice-oriented research in psychodrama. http://www.fepto.com/wp-content/uploads/ RC-Lisbon-report.pdf. Accessed 19 Sept 2018.

Kunz Mehlstaub, S., \& Stadler, Ch (2018). Psychodrama-Therapie. Stuttgart: Kohlhammer.

Lambert, M.J. (2010). Prevention of treatment failure: The use of measuring, monitoring, \& feedback in clinical practice. Washington, DC: APA Press.

Lambert, M. J. (2017). Integration of methods for preventing treatment failure into routine practice: Why \& how clinicians need to change aspects of routine care. Third International Conference on Integration in Psychotherapy, Warsaw, Poland.

Llewelyn, S. (1988). Psychological therapy as viewed by clients and therapists. British Journal of Clinical Psychology, 27, 223-238. https://doi.org/10.1111/j.2044-8260.1988.tb00779.x.

Sales, C. (2015). Practice-based studies in psychodrama. http://www.fepto.com/wp-content/uploads/RCLisbon-report.pdf. Accessed 20 Sept 2018.

Sales, C., \& Alves, P. (2016). Patient-centered assessment in psychotherapy: A review of individualized tools. Clinical Psychology: Science and Practice, 23(3), 265-283. https://doi.org/10.1111/cpsp. 12162 .

Sağin, B.H., \& Altan Egean, A. (2017). Evaluation of psychodrama group processing qualitative data analysis. http://www.fepto.com/wp-content/uploads/Skopje-FEPTO-RCM-2017-final-report.pdf. Accessed 20 Sept 2018.

Schaller, R. (2016). Stellen Sie sichvor, Sie sind... Das Ein-Personen-Rollenspiel in Beratung, Coaching und Therapie (2nd edn.). Bern: Hogrefe.

Shimokawa, K., Lambert, M. J., \& Smart, D. (2010). Enhancing treatment outcome of patients at risk of treatment failure: Meta-analytic \& mega-analytic review of a Psychotherapy Quality Assurance Program. Journal of Consulting \& Clinical Psychology, 78, 298-311.

Stadler, Ch (2014). Psychodrama. München: Ernst Reinhardt Verlag.

Thayer, S.D., \& Burlingame, G. M. (2014). The validity of the group questionnaire: Construct clarity or construct drift? Group Dynamics: Theory, Research, and Practice, 18(4), 318-332. https://doi.org/ $10.1037 / g d n 0000015$. 


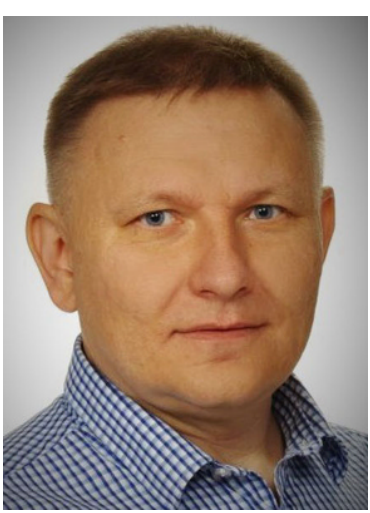

Krzysztof Mariusz Ciepliński PhD, 1972, is a psychologist, psychodramatist and integrative psychotherapist, trainer, researcher and lecturer at The John Paul II Catholic University of Lublin, Poland and also the Vice President of FEPTO and former Co-chair of the FEPTO Research Committee. He provides group, individual and couple psychotherapy. His research interests include psychodrama outcome and change process studies, integration of psychotherapy and psychology of freedom experiencing.

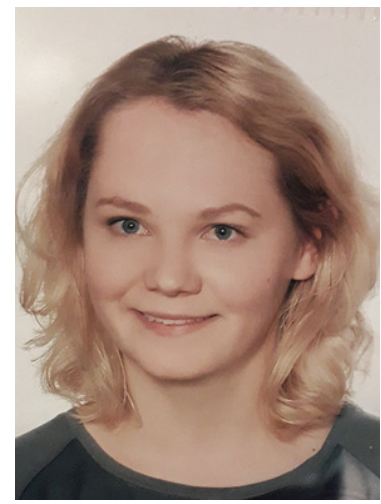

Joanna Karkut-Rzondtkowska 1993, is a psychology graduate of The John Paul II Catholic University of Lublin, Poland; interested in HR, business psychology and psychodrama. Currently supports companies with recruitment and HR processes. 